Original Article

\title{
DRUG UTILISATION STUDY OF STROKE AND OTHER PATIENTS ADMITTED TO GENERAL WARD OF NEUROLOGY UNIT AT QUATERNARY CARE PRIVATE HOSPITAL
}

\author{
LAXMAN WAGLE ${ }^{*}$, ABEL ABRAHAM THOMAS ${ }^{2}$, SUNIL SHRESTHA ${ }^{3}$ \\ 1, 2Department of Pharmacy Practice, Sri Adichunchanagiri College of Pharmacy, BG Nagara, Mandya District, Karnataka India, 571448, \\ ${ }^{3}$ Department of Pharmacy, Kathmandu University, Kavre, Nepal \\ Email: waglelaxman@gmail.com \\ Received: 27 Jan 2017, Revised and Accepted: 20 Apr 2017
}

\section{ABSTRACT}

Objective: To study the profile of the patient, the pattern of their illness and their drug use patterns attending to general ward of quaternary care hospital.

Methods: Prospective observational study of 2 mo was performed at neurology unit of the quaternary care private hospital, India. Patients aged above $20 \mathrm{y}$ with at least one neurological drug in prescription were included to observe their demographic profile, illness pattern and drug use. The data was analysed and summarised as frequency and percentage using microsoft excel and presented as tables.

Results: Among 60 patient that were enrolled, more were males $(\mathrm{N}=33,55 \%)$ than females $(\mathrm{N}=27,45 \%)$ and within the age group of $60-70$ y $(\mathrm{N}=22$, $36.67 \%)$. The majority of patients were diagnosed with strokes $(\mathrm{N}=48,80 \%)$ where the cerebrovascular accident was most common $(\mathrm{N}=16,26.66 \%)$. Males $(\mathrm{N}=29,60.4 \%)$ were more prone to get stroke than females $(\mathrm{N}=19,39.6 \%)$. An average number of drugs per prescription was 5.7 , the percentage of antibiotics, generic drugs and injections were $36.6 \%, 0.05 \%$ and $44.14 \%$ respectively. A total of 28 different drug classes with 61 different drugs was utilised. Fourteen drug classes had been accounted for $90 \%$ of drugs utilisation. Clopidegrol+Aspirin have frequently used the drug.

Conclusion: Most people attending neurology unit were elderly. Stroke occupies $1^{\text {st }}$ list for the burden. Average drugs for neurology visit remain high. Wide types of drug classes are utilised in neurological wards.

Keywords: Neurology department, Drug utilisation, Profile of stroke patients

(c) 2017 The Authors. Published by Innovare Academic Sciences Pvt Ltd. This is an open access article under the CC BY license (http://creativecommons.org/licenses/by/4.0/) DOI: http://dx.doi.org/10.22159/ijcpr.2017v9i4.20630

\section{INTRODUCTION}

The overall global burden of neurologic disease is approximately $20 \%$, the majority being in the developing countries causing morbidity, mortality and adversely affecting the quality of life [1, 2]. Major neurological disorders include stroke, dementia epilepsy, headache disorders, multiple sclerosis, Parkinson's disease, traumatic brain injuries, neuroinfectious, pain associated with neurological disorders and neurological disorder associated with malnutrition. Pharmacotherapy is an important aspect for the management of neurological diseases [3]. Common drug class utilized in neurological disorders include cholinesterase inhibitors, antiparkinson, antiplatelets, anticoagulants and thrombolytic, anti-epileptics, sedatives and hypnotics, antidepressants, antipsychotics, non-steroidal antiinflammatory drugs, triptans, steroids, vitamin supplements, specific biological therapies etc [4]. The increased interest of drug utilisation research in neurology has resulted from the increased marketing of new drugs, the wide variation in the pattern of drug prescribing and consumption and increasing concern about the cost of neurological drugs. The studies related to drug utilization in neurology is limited in India [2]. Drug utilisation research (DUR) was defined by 'World Health Organisation' (WHO) in 1977 as 'Marketing, distribution, prescription and use of drugs in society with special emphasis on resulting medical,social and economic implication [5]. Such studies have to be carried out from time to time. Drug utilisation study, especially at neurology department in India, is very less. Keeping these things in mind we conducted single centred prospective study in neurological inpatient department at the quaternary hospital with objectives to study the profile of patients admitting to the neurological department, to study the prescriptions based on WHO prescribing indicator and to identify utilisation pattern of drugs.

\section{MATERIALS AND METHODS}

\section{Study design}

Prospective, observational and one centre study.
Source of data and materials

Patient prescriptions, patient case sheets, data collection form.

\section{Inclusion criteria}

Patients of either sex suffering from neurological disorder comming to general wards of neurological inpatient department who aged above $20 \mathrm{y}$ and having at least one neurological drug in prescription.

Exclusion criteria

Pregnant and lactating women, a paediatric patient, outpatients.

Method of collection of data

Following data was collected in customised data collection form like patient demographic details, patient diagnosis, prescription details like: date, prescription number, number of drugs in prescription, name of individual drug, its route, dosage form, dosing schedule or frequency and duration of therapy, number of drugs prescribed by generic name, number of drugs prescribed from 'National essential medicine list' and number of injectable drugs prescribed.

Study procedure and data analysis

A patient who met above inclusion and exclusion criteria were only enrolled. Details regarding demographics, diagnosis, treatment etc were collected from the case sheet/prescription in suitably designed data collection form. WHO prescribing indicators were used in the study to assess drug use which included an average number of drugs per prescription, the percentage of drug prescribed by generic name, the percentage of a prescription containing at least one generic, the percentage of injections prescribed, the percentage of antibiotic prescribed. Drugs were classified first and reported as frequency and percentage to show extent (frequent and infrequent) of their utilisation. For drug interaction, drug information resources like 'Medscape Drug Interaction Checker', 'Stockley's Drug Interaction' 
was reviewed. Only major and significant interactions were mentioned. The data were analysed using suitable descriptive statistics and represented in tables with the aid of microsoft excel.

Does the study require any investigation or interventions to be conducted on the patients?

No. It did not require any investigation/intervention to the patient.

\section{Study sample}

60 patients were enrolled during the study period.

\section{Study period}

This study was conducted for a period of 2 mo (December 2015 to January (2016)

\section{Study site}

Study was conducted in the neurology department of Quaternary care private hospital, India, Bangalore.

\section{RESULTS}

\section{Profile of patient demographics}

We observed males $(\mathrm{N}=33,55 \%)$ were more than females $(\mathrm{N}=27,45 \%)$.
Stratification based on age showed patients admitting to general neurological ward were frequently within the age group of 60-70 y $(\mathrm{N}=32,36.6 \%)$ followed by $20-30$ y $(\mathrm{N}=10,16.66 \%), \quad 40-50$ $(\mathrm{N}=8,13.33 \%)$ and $50-60 \mathrm{y}(\mathrm{N}=8,13.33 \%), 70-80 \mathrm{y}(\mathrm{N}=6,10 \%), 30-40$ $\mathrm{y}(\mathrm{N}=4,6.66 \%)$ and $80-90 \mathrm{y}(\mathrm{N}=2,3.33 \%)$ respectively as shown in table $1(\mathrm{a})$. We found more stroke cases $(\mathrm{N}=48,80 \%)$ in comparison to other illness $(\mathrm{N}=12,12 \%)$.

For stroke 60-70 y (mean age group 61.52 \pm 16.2 ) was most common to happen as shown in table 1(b). We found that in stroke cases $(\mathrm{N}=48)$, males $(\mathrm{N}=29,60.4 \%)$ were more than females $(\mathrm{N}=19$, $39.6 \%)$ whereas in illness other than stroke $(\mathrm{N}=12)$ females were more $(\mathrm{N}=8,66.67 \%)$ to males $(\mathrm{N}=4,33.33 \%)$ as shown in table $1(\mathrm{c})$.

\section{Profile of patient diagnosis visiting neurological ward}

Among 60 patients studied, stroke was the most common reason for admission in $80 \%$ of cases followed by patients without stroke (20\%). Cerebrovascular accident was the most common $(\mathrm{N}=16$, $26.66 \%$ ) diagnosis of a stroke followed by acute left middle carotid artery infarct $(\mathrm{N}=8,13.33 \%)$, transient ischemic attack $(\mathrm{N}=6,10 \%)$, right basal ganglia infarct $(\mathrm{N}=6,10 \%)$ and others as shown in table 2 . In illness other than stroke seizure $(10 \%)$ followed by multiple sclerosis $(3.33 \%)$, migraine $(3.33 \%)$ and herpes zoster infection $(3.33 \%)$ were the different diagnosis.

Table 1(a): Profile of patient demographics: age and sex distribution

\begin{tabular}{|c|c|c|c|c|c|c|c|c|}
\hline Sex/Age (y) & $20-30$ & $30-40$ & $40-50$ & $50-60$ & $60-70$ & $70-80$ & $80-90$ & Total (\%) \\
\hline Male & 6 & 4 & 2 & 2 & 15 & 4 & 0 & $33(55 \%)$ \\
\hline Female & 4 & 0 & 6 & 6 & 7 & 2 & 2 & $27(45 \%)$ \\
\hline Total $(\mathrm{N}, \%)$ & $10(16.66 \%)$ & $4(6.66 \%)$ & $8(13.33 \%)$ & $8(13.33 \%)$ & $22(36.67 \%)$ & $6(10 \%)$ & $2(3.33 \%)$ & $60(100 \%)$ \\
\hline
\end{tabular}

Table 1(b): Profile of patient demographics: diagnosis and age distribution

\begin{tabular}{llllllllll}
\hline Diagnosis/Age (y) & $\mathbf{2 0 - 3 0}$ & $\mathbf{3 0 - 4 0}$ & $\mathbf{4 0 - 5 0}$ & $\mathbf{5 0 - 6 0}$ & $\mathbf{6 0 - 7 0}$ & $\mathbf{7 0 - 8 0}$ & $\mathbf{8 0 - 9 0}$ & Mean age (years) & Total (\%) \\
\hline Stroke & 3 & 3 & 7 & 8 & 20 & 5 & 2 & $61.52 \pm 16.2$ \\
Non stroke & 7 & 1 & 1 & 0 & 2 & 1 & 0 & $48(80 \%)$ \\
\hline
\end{tabular}

Table 1(c): Profile of patient demographics: diagnosis and sex distribution

\begin{tabular}{lllc}
\hline Diagnosis & Male (N, \%) & Female (N, \%) & Total (\%) \\
\hline Stroke & $29(60.4 \%)$ & $19(39.6 \%)$ & $48(80 \%)$ \\
Non stroke & $4(33.33 \%)$ & $8(66.67 \%)$ & $12(20 \%)$ \\
\hline
\end{tabular}

Table 2: Profile of patient diagnosis visiting neurological ward

\begin{tabular}{lll}
\hline Diagnosis & Frequency & Percentage (\%) \\
\hline Stroke & 48 & $80 \%$ \\
Corona radiata infarct & 2 & $3.333 \%$ \\
Right front parietal limb infarct & 2 & $3.33 \%$ \\
Right basal ganglia infarct & 6 & $10 \%$ \\
Cerbrovascular accident & 16 & $26.66 \%$ \\
Cerebral venous sinus thrombosis & 4 & $6.666 \%$ \\
Acute left middle carotid artery infarct & 8 & $13.33 \%$ \\
Lateral medullary syndrome & 2 & $3.33 \%$ \\
Left hemiparesis & 2 & $3.33 \%$ \\
Transient ischaemic attack & 6 & $10 \%$ \\
Diagnosis other than stroke & 12 & $20 \%$ \\
Herpes zoaster infection & 2 & $3.33 \%$ \\
Migrane & 2 & $3.33 \%$ \\
Multiple sclerosis & 2 & $3.33 \%$ \\
Seizure & 2 & $10 \%$ \\
Total & 6 & $100 \%$ \\
\hline
\end{tabular}

\section{Assessment of WHO prescribing indicators}

We observed 342 medicines were prescribed in 60 prescriptions. Average number of drugs in prescription was 5.7.
Percentage of injections prescribed was found to be $44.14 \%$. Percentage of patients with antibiotics was more i.e. $36.6 \%$ Percentage of generic drugs prescribed was very less $(0.05 \%)$. 
Table 3: WHO prescribing indicators

\begin{tabular}{ll}
\hline WHO prescribing indicators & Total \\
\hline Number of patient cases reviewed & 60 \\
Number of drugs utilised & 342 \\
Average number of drugs per prescription & 5.7 \\
\% of generic drugs prescribed & $0.05 \%$ \\
\% of drugs in injections prescribed & $44.14 \%$ \\
$\%$ of patients with antibiotics & $36.6 \%$ \\
\hline
\end{tabular}

\section{Utilisation pattern of drugs: classification}

The utilisation of various drugs and its classification was presented in table 4(a) and 4(b). Total of 28 different drug classes was used with 61 different drugs. Fourteen different classes i.e. only half of the classes that were utilised had been accounted for $90 \%$ of drugs utilisation which included antiplatelets $(\mathrm{N}=48,14.61 \%)$, anticoagulant $(\mathrm{N}=34,9.94 \%)$, supplements $(\mathrm{N}=32,9.35 \%)$, antihypertensives $(\mathrm{N}=32,9.35 \%)$, antiepileptics $(\mathrm{N}=28,8.18 \%)$, proton pump inhibitors $(\mathrm{N}=26,7.6 \%)$, nootropics $(\mathrm{N}=24,7.01 \%)$, antibiotics $(\mathrm{N}=22,6.43 \%)$, hypolipidemic $(\mathrm{N}=20,5.84 \%)$, antipyretics $(\mathrm{N}=18,5.26 \%)$, bronchodilators $(\mathrm{N}=8,2.33 \%)$, antidiabetics $(\mathrm{N}=6,1.75 \%)$, steroids $(\mathrm{N}=6,1.75 \%)$, antidepressants $(\mathrm{N}=4,1.16 \%)$ respectively. Very infrequently used a class of drugs included analgesic, alkaliser, antidiarrheal, antiemetics, antipsychotics, antiviral, cardiac inotropic, central acetylcholinesterase inhibitor, eugeroic agent, laxative, sedative and leukotriene receptor antagonist.

Table 4(a): Utilisation pattern of drugs: classification

\begin{tabular}{|c|c|c|c|c|}
\hline S. No. & Class of drug & Frequency (N) & Percentage (\%) & Indication (stroke or other than stroke?) \\
\hline 1. & Antiplatelets & 48 & $14.61 \%$ & Stroke \\
\hline 2. & Anticoagulants & 34 & $9.94 \%$ & Stroke \\
\hline 3. & Antihypertensives & 32 & $9.35 \%$ & Stroke \\
\hline 4. & Supplements & 32 & $9.35 \%$ & $\begin{array}{l}\text { Non Stroke }=4 \\
\text { Stroke }=28\end{array}$ \\
\hline 5. & Antiepileptic & 28 & $8.18 \%$ & $\begin{array}{l}\text { Non stroke }=6 \\
\text { Stroke }=22\end{array}$ \\
\hline 6. & Proton pump inhibitors & 26 & $7.60 \%$ & $\begin{array}{l}\text { Non stroke }=2 \\
\text { Stroke }=24\end{array}$ \\
\hline 7. & Nootropic & 24 & $7.01 \%$ & Stoke \\
\hline 8. & Antibiotics & 22 & $6.43 \%$ & $\begin{array}{l}\text { Stroke }=20 \\
\text { Non stroke }=2\end{array}$ \\
\hline 9. & Hypolipidemics & 20 & $5.84 \%$ & Stroke \\
\hline 10. & Antipyretic & 18 & $5.26 \%$ & Stroke \\
\hline 11. & Bronchodilators & 8 & $2.33 \%$ & Stroke \\
\hline 12. & Antidiabetic & 6 & $1.75 \%$ & Stroke \\
\hline 13. & Steroids & 6 & $1.75 \%$ & $\begin{array}{l}\text { Non stroke }=2 \\
\text { Stroke }=4\end{array}$ \\
\hline 14. & Antidepressants & 4 & $1.16 \%$ & Stroke \\
\hline 15. & Muscle relaxants & 4 & $1.16 \%$ & Non-stroke \\
\hline 16. & Potassium-sparing agent & 4 & $1.16 \%$ & Stroke \\
\hline 17. & Analgesic & 2 & $0.58 \%$ & Nonstroke \\
\hline 18. & Alkaliser & 2 & $0.58 \%$ & Nonstroke \\
\hline 19. & Antidiarrheal & 2 & $0.58 \%$ & Stroke \\
\hline 20. & Antiemetics & 2 & $0.58 \%$ & Stroke \\
\hline 21. & Antipsychotic & 2 & $0.58 \%$ & Nonstroke \\
\hline 22. & Antiviral & 2 & $0.58 \%$ & Nonstroke \\
\hline 23. & Cardiac inotropic & 2 & $0.58 \%$ & Stroke \\
\hline 24. & Central acetyl cholinesterase inhibitor & 2 & $0.58 \%$ & Nonstroke \\
\hline 25. & Eugeroic agent & 2 & $0.58 \%$ & Stroke \\
\hline 26. & Laxative & 2 & $0.58 \%$ & Stroke \\
\hline 27. & Sedative & 2 & $0.58 \%$ & Nonstroke \\
\hline 28. & Leukotriene recepter antagonist & 2 & $0.58 \%$ & Stroke \\
\hline 29. & Total & 342 & $100 \%$ & \\
\hline
\end{tabular}

\section{Utilisation pattern of drugs: nature and extent of drug use}

61 different drugs were utilised in total of 60 patients which was as shown in table 4(b). Most frequently Clopidegrol+Aspirin (13.45\%) was used followed by Enoxaparin Sodium (8.77\%), Citicholine (7.01\%), Supplement Drugs (6.43\%), Pantoprazole (6.43\%), Atorvastatin (5.84\%), Paracetamol (5.26\%), Levetiracetam (3.5\%), Salbutamol+Ipratropium (2.33\%), Telmisartan (1.7\%), Amlodipine (1.7\%), Amoxicillin+Clavulanate (1.7\%), Piperacillin+Tazobactam $(1.16 \%)$, Ceftriaxone (1.16\%), Vancomycin (1.16\%), Warfarin (1.16\%), Phenytoin (1.16\%), Clobazam (1.16\%), Gabapentin (1.16\%), Prazocin (1.16\%), Carvedilol (1.16\%), Aspirin (1.16\%), Baclofen $(1.16 \%)$, Spirinolactone $(1.16 \%)$, Sodium Bicarbonate $(0.58 \%)$, Diclofenac $(0.58 \%)$, Doycycline, $(0.58 \%)$, Levofloacin
(0.58\%), Amitriptyline+Chlordiazepoxide $(0.58 \%)$, Amitriptyline $(0.58 \%)$, Metformin+Glimepiride (0.58\%), Insulin $(0.58 \%)$, Metformin (0.58\%), Metronidazole (0.58\%), Ondansetron $(0.58 \%)$, Fosphenytoin $(0.58 \%)$,Escitalopram $(0.58 \%)$, Atenolol $(0.58 \%)$, Metoprolol (0.58\%), Furosemide $(0.58 \%)$, Furosemide +Spirinolactone $(0.58 \%)$, Telmisartan+Hydrochlorthiazide $(0.58 \%)$, Verapamil (0.58\%), Quetiapine Fumarate (0.58\%), Acyclovir $(0.58 \%)$, Digoxin $(0.58 \%)$, Donepezil $(0.58 \%)$, Modafinil $(0.58 \%)$, Lactulose $(0.58 \%)$, Potassium Chloride $(0.58 \%)$, Rabeprazole $(0.58 \%)$, Rabeprazole+Domperidone $(0.58 \%)$, Zolpidem $(0.58 \%)$, Monteleukast $(0.58 \%)$, Methylprednisolone $(0.58 \%)$, Budesonide $(0.58 \%)$, Dexamethasone $(0.58 \%)$, Ferrous Salt $(0.58 \%)$, Calcium+Calcitriol $(0.58 \%)$, Homocysteine $(0.58 \%)$, Levothyroxin (0.58\%). 
Table 4 (b): Utilisation pattern of drugs: nature and extent of drug use

\begin{tabular}{|c|c|}
\hline Name of utilised drug & Frequency of drug (\%) \\
\hline Clopidogrel+Aspirin & $46(13.45 \%)$ \\
\hline Enoxaparin Sodium & $30(8.77 \%)$ \\
\hline Citicoline & $24(7.01 \%)$ \\
\hline Pantoprazole & $22(6.43 \%)$ \\
\hline Other Combination preparations & $22(6.43 \%)$ \\
\hline Atorvastatin & $20(5.84 \%)$ \\
\hline Paracetamol & $18(5.26 \%)$ \\
\hline Levetiracetam & $12(3.5 \%)$ \\
\hline Salbutamol+Ipratropium & $8(2.33 \%)$ \\
\hline Amoxicillin+Clavulanate & $6(1.7 \%$ \\
\hline Amlodipine & $6(1.7 \%)$ \\
\hline Telmisatan & $6(1.7 \%)$ \\
\hline Piperacillin+Tazobactam & $4(1.16 \%)$ \\
\hline Ceftriaxone & $4(1.16 \%)$ \\
\hline Vancomycin & $4(1.16 \%)$ \\
\hline Warfarin & $4(1.16 \%)$ \\
\hline Phenytoin & $4(1.16 \%)$ \\
\hline Clobazam & $4(1.16 \%)$ \\
\hline Gabapentin & $4(1.16 \%)$ \\
\hline Prazosin & $4(1.16 \%)$ \\
\hline Carvedilol & $4(1.16 \%)$ \\
\hline Aspirin & $4(1.16 \%)$ \\
\hline Baclofen & $4(1.16 \%)$ \\
\hline Spirinolactone & $4(1.16 \%)$ \\
\hline Sodium Bicarbonate & $2(0.58 \%)$ \\
\hline Diclofenac & $2(0.58 \%)$ \\
\hline Doxcycline & $2(0.58 \%)$ \\
\hline Levofloxacin & $2(0.58 \%)$ \\
\hline Amitriptyline+Chlordiazepoide & $2(0.58 \%)$ \\
\hline Amitriptyline & $2(0.58 \%)$ \\
\hline Glimepiride+Metformin & $2(0.58 \%)$ \\
\hline Insulin & $2(0.58 \%)$ \\
\hline Metformin & $2(0.58 \%)$ \\
\hline Metronidazole & $2(0.58 \%)$ \\
\hline Odansetron & $2(0.58 \%)$ \\
\hline Fosphenytoin & $2(0.58 \%)$ \\
\hline Escitalopram & $2(0.58 \%)$ \\
\hline Atenolol & $2(0.58 \%)$ \\
\hline Metoprolol & $2(0.58 \%)$ \\
\hline Furosemide & $2(0.58 \%)$ \\
\hline Furosemide+Spirinolactone & $2(0.58 \%)$ \\
\hline Telmisartan+Hydrochlorthiazide & $2(0.58 \%)$ \\
\hline Verapamil & $2(0.58 \%)$ \\
\hline Quetiapine Fumarate & $2(0.58 \%)$ \\
\hline Acyclovir & $2(0.58 \%)$ \\
\hline Digoxin & $2(0.58 \%)$ \\
\hline Donepezil & $2(0.58 \%)$ \\
\hline Modafinil & $2(0.58 \%)$ \\
\hline Lactulose & $2(0.58 \%)$ \\
\hline Potassium Chloride & $2(0.58 \%)$ \\
\hline Rabeprazole & $2(0.58 \%)$ \\
\hline Rabeprazole+Domperidone & $2(0.58 \%)$ \\
\hline Zolpidem & $2(0.58 \%)$ \\
\hline Monteleukast & $2(0.58 \%)$ \\
\hline Methylprednisolone & $2(0.58 \%)$ \\
\hline Budesonide & $2(0.58 \%)$ \\
\hline Dexamethasone & $2(0.58 \%)$ \\
\hline Ferrous Salt & $2(0.58 \%)$ \\
\hline Calcium+Calcitriol & $2(0.58 \%)$ \\
\hline Homocysteine & $2(0.58 \%)$ \\
\hline Levothyroxin & $2(0.58 \%)$ \\
\hline Total & $342(100 \%)$ \\
\hline
\end{tabular}

\section{DISCUSSION}

Our study means that as age advances there is frequent chance to have a neurological illness which is in conjuncture with other result findings [6, 7]. Our research also means that males were more prone to be admitted. Probably the age and sex related increase in cerebrovascular event have made the neurological problems a common ailment in many studies including our research [8]. Our study reveals that stroke is being a major burden to neurological illness. Stroke as the common diagnosis was also observed in the study by Rajiv Narayan Chaudary where he observed stroke in $47.5 \%$ cases followed by seizure in $9.3 \%$ cases and other illness out of 335 different neurological cases [6]. In diagnosis other than stroke; seizure was also the common illness $(10 \%)$ in our study 
which shows the similarity of findings. In our centre, the cerebrovascular accident was a most common diagnosis of stroke but it can varies from region to region. Most people with stroke were between $60-70 \mathrm{y}$ in the age group which is similar to study by Mohammad Yaseen Abbasi [9]. In contrast manner, other study found common age group for experiencing stroke were between 4160 y (50\%) followed by 61-80 y (37.33\%) [10]. Other related study was done by R P Eapen [11] and Naik M [12] found the mean age as 57 and 58.27 y respectively which is similar $(61.52 \pm 16.2)$ to our study. Our study also shows that being a male has more chances of stroke in conjuncture with a couple of other similar research $[9,13]$. One reason may be due to different sex steroid hormones, notably estrogens and testosterone. Estrogens have terribly potent effects on endothelia that promote dilation and blood flow whereas testosterone has opposing effect indicating women are protecting with endogenous estrogens [14]. Stroke causes 0.6 million death in India and annual incidence was being 145/100,000 per year during 2003 to 2006 [15] is increasing on an alarming rate. The situation is slightly different in European countries (except for the Irish) where studies had reported epilepsy as a major cause of neurology visit and then stroke $[16,17]$. These differences may be attributed to lifestyle and health consciousness level of peoples of the developed world. In one similar study at Nepal, The most common neurological disorders admitted in their setup were cerebrovascular diseases, seizure disorders, inflammatory and infective diseases; stroke being the major cause of consultation. It also shows the similarities to our findings [7]. In order of frequency the most common reason for referral in another similar study was stroke (131 cases $(22.7 \%))$, seizures unrelated to alcohol (59 cases (10.2\%)), alcohol-related neurological problems (55 cases $(9.5 \%))$, movement disorders (41 cases $(7.1 \%))$, neuromuscular (40 cases $(6.9 \%)$ ), coma (35 cases $(6 \%)$ ), disorders of cognition (31 cases (5.3\%)), acute headache (28 case $(4.8 \%))$ and functional neurological syndromes (26 cases (4.5\%)) [8].

Prescribing indicators assess the drug use problems in prescriptions from rationality standpoint. Among different indicators drugs per prescription is high (5.7). This number is high in relation to get drugdrug interaction. In fact we observed prescription which can theoretically cause effects of drug interaction like Telmisartan+ Aspirin, Enoxaparin+Telmisartan, Pantoprazole+ Clopidogrel, Telmisartan+Atorvastatin, Spironolactone+Atorvastatin, Aspirin+ Metoprolol, Enoxaparin+Diclofenac, Metoprolol+ Spirono-lactone, Spironolactone+Aspirin, Spironolactone+Diclofenac, Aspirin+ Diclofenac, Verapamil+Aorvastatin+Verapamil+Clopidegrol, Verapamil+ Atorvastatin, Amlodipine+Veramapil, Verapamil+Aspirin, Aspirin+ Clopidegrol and Enoxaparin+Warfarin. Close and careful monitoring was done to these patients to optimise therapy. Athira Jith and colleagues performed drug-drug interaction study among stroke patients in tertiary care hospital at Tamil Nadu, India where they observed 698 potential drug-drug interactions out of which 18 were clinically significant [18]. Our research has also highlighted less generic name prescribing by physicians. WHO recommends a prescription to write in generic name format to increase patient compliance but is not happening. One reason is a lack of hospital formulary concept in hospitals.

There is few drug utilisation study conducted in the neurology department at quaternary care hospitals in India to compare with other studies. Sangram Vurumadla and co-workers had observed prescribing pattern focusing on stroke where they observed utilisation of drugs like Mannitol, Aspirin, Clopidegrol, Atorvastatin, Nifedipine, Multivitamin, Enoxaparin, Phenytoin, Atenolol, Losartan, Heparin, Ramipril and Ramipril+Telmisartan+hydrochlorothiazide in descending frequencies [10]. Unlike their study, we observed the use of a combination of Clopidegrol+Aspirin instead of clopidegrol only for stroke in our study. Apart from this combination, we found the use of drugs like Enoxaparin sodium, Citicholine, Warfarin and aspirin in descending frequencies for stroke. Antihypertensives like B-blockers, diuretics and calcium channel blockers were used to reduce target BP for these patients. Kuriakose and co-authors from Tamil Nadu, India found an antihypertensive drug to be utilised more commonly besides antiplatelets therapy [19]. It shows the fact that antihypertensive were frequently used agents for stroke patients. In another study by Silverman, various drugs were prescribed in stroke patients such as anticoagulants, antiplatelet drugs, dyslipidemics, anti-hypertensive, neurotonics. Drugs to be administered for conditions occurring after the initial event (depression, dementia, and epilepsy) like antiepileptics, antipsychotics, CNS stimulants were also prescribed for the patients [20-22]. Our result is in conjuncture to these findings. Primary management of stroke includes antiplatelet therapy with aspirin, statin therapy and blood pressure management. Primary prevention interventions are expected to target at behavior modification such as reduced smoking, alcohol and salt consumption patterns and increased physical activity. Increasing fruit and vegetable consumption (for each 1-serving per day) is considered to reduce the risk of stroke by $6 \%$. In one study by Andhuvan $\mathrm{G}$ and colleagues found that most participants had poor knowledge about modifiable risk factors and concluded that it could increase their chance of cardiovascular risk in future [23]. Secondary prevention is through the pharmacological therapy. Tertiary prevention is attributed to maintain their ability to carry out daily activities if they receive rehabilitation services at home. Stroke rehabilitation is expected to begin as soon as possible after a person has a stroke and continue for as long as it is clinically appropriate [20]. Treatment pattern of illness other than stroke involved specific pharmacological agents like central cholinesterase inhibitors for multiple sclerosis, antiepileptic's like Levetiracetam, Gabapentin, Phenytoin, Phosphenytoin, Clobazam for seizures related to stroke or epilepsy. For migraine Diclofenac was the drug of choice and for herpes zoaster infection, steroids like Dexamethasone and Methyl Prednisolone were used primarily. Other agents were for symptomatic treatment like antibiotics, alkaliser's, supplements, antipyretics, laxatives, sedative-hypnotics, antidepressants, antidiabetics etc.

Our study provides drug exposure data of inpatients visting neurological department for a different illness. Small sample size and short duration remained the limitation of our study.

\section{CONCLUSION}

Most of the patient attending neurology unit were senior citizens. Stroke occupies top most burdens. We observed high drugs per prescription for neurology visits and very less generic prescribing. Various types of drugs were used depending on the illness. In a stroke, Clopidegrol and Aspirin combination was utilised most commonly. A primary prevention strategy to reduce highly prevalent neurological cases like stroke is needed.

\section{ACKNOWLEDGEMENT}

We would like to thank professor and principal, B. Ramesh, Sri Adichunchanagiri College of Pharmacy, BG Nagara Mandya District, Karnataka India, 571448 for constant support.

\section{AUTHORS CONTRIBUTION}

It was a collaborative work between all the authors listed. Dr. Abel Abraham Thomas (PharmD), Dr. Sunil Shrestha (PharmD; Post Baccalaureate) and Dr. Laxman Wagle (PharmD; Post Baccalaureate) were responsible for literature review, proposal writing, data collection and data entry. Dr. Laxman Wagle was responsible for data analysis, manuscript writing and communication.

\section{CONFLICT OF INTERESTS}

\section{Declare none}

\section{REFERENCES}

1. Burton KJ, Allen S. A review of neurological disorders presenting at a paediatric neurology clinic and response to anticonvulsant. Ann Trop Pediatric 2003;23:139-43.

2. Raina SK, Razdan S, Nanda R. Prevalence of neurological disorders in children less than $10 \mathrm{y}$ of age in RS Pura town of Jammu and Kashmir. J Pediatr Neurosci 2011;6:103-5.

3. WHO report-Neurological disorder, public health challenge; 2006.

4. http://www.medscape.org/neurology. [Last accessed on 15 Dec 2016].

5. Introduction to Drug Utilization Research by World Health Organization; 2013. 
6. Chowdhury RN, Hasan H, Rahman YU, Khan IS, Hussain AR, Ahsan S. Pattern of neurological disease seen among patients admitted in tertiary care hospital. BMC Res Notes 2014;7:1-5.

7. Gajurel BP, Parajuli P, Nepali R, Oli KK. Spectrum of neurological disorders admitted in Tribhuvan University Teaching Hospital Maharajgunj. J Inst Med 2012;34:50-3.

8. Costello DJ, Renganathan R, Hare AO, Murray B, Lynch T. Audit of an inpatient neurology consultation service in a tertiary referral centre: the value of the consulting neurologist. Ir Med J 2005;98:134-7.

9. Abbasi YM, Ali MA. Prescribing pattern of drugs in strokes patients. Arch Pharm Pract 2012;3:283-8.

10. Vurumadla S, Rakshith V, Murari CH, Venkateshwarlu K. A study on symptoms, risk factors and prescribing pattern of drugs used in stroke patients. Int J Pharm Pharm Sci 2015;7:421-6.

11. Eapen RP, Parikh JP. A study on clinical profile and risk factor of cerebrovascular stroke. Gazi Med J 2009;64:47-54.

12. Naik M, Rauniyar RK. Clinicoradiological profile of stroke in eastern Nepal: a computed tomographic study. Kathmandu University Med J 2006;4:161-6.

13. Kumar SV, Damodar G, Ravikanth S, Vijayakumar G. Drug utilization pattern of stroke patients in a tertiary care hospital. Int J Curr Pharm Clin Res 2012;2:3-7.

14. Mathew JR, Cheryl DB, George H. Sex differences in stroke, epidemiology, clinical presentation, medical care and outcomes. Lancet Neurol 2008;7:915-26.

15. Murray CJL, Lopez AD. The global burden of disease: a comprehensive assessment of mortality and disability from diseases, injuries, and risk factors in 1990 and projected to 2020. $1^{\text {st }}$ edition. Harvard University Boston: The Harvard school of public health on behalf of the world health organization and the World Bank; 1996.

16. Weatherall MW. Acute neurology in a twenty-first-century district general hospital. J R Coll Physicians Edinb 2006;36:196-200.

17. Chapman FA, Pope AE, Sorensen D, Knight RS, Salman ASR. The uses of a rapid access neurology clinic. J R Coll Physicians Edinb 2009;39:296-300.

18. Athira J, Chaithanya KT, Joffey SJ, Kavitha SP, Sambath KR. A prospective study of drug-drug interactions and adverse drug reactions among stroke patients in a tertiary care hospital. Asian J Pharm Clin Res 2016;9 Suppl 3:100-4.

19. Kuriakose C, Shifafiya MN, Sekar V, Sambath KR. To evaluate the prevalence and drug prescribing trends in stroke patients: a retrospective study. Int J Chem Pharm Sci 2014;5:22-7.

20. Silverman IE. Post-stroke seizures. Arch Neurol 2002;59:194-202.

21. Kanji S, Corman C, Douen AG. Blood pressure management in acute stroke: comparison of current guidelines with prescribing patterns. Can J Neurol Sci 2002;29:125-31.

22. Po HL, Lin YJ, Hseuh IH. The prescribing patterns of antithrombotic agents for prevention of recurrent ischemic stroke. Acta Neurol Taiwan 2009;18:98-103.

23. Andhuvan G, Ayyappan P, Sahana C, Poovizhi S, Sivasakthi K. Knowledge of modifiable risk factors of heart disease among patients with cardiovascular ris. Asian J Pharm Clin Rres 2017;10:99-102.

\section{How to cite this article}

- Laxman Wagle, Abel Abraham Thomas, Sunil Shrestha. Drug utilisation study of stroke and other patients admitted to general ward of neurology unit at quaternary care private hospital. Int J Curr Pharm Res 2017;9(4):23-28. 